\title{
DESIGN OF MODELING AND SIMULATION FOR TRAIN TRACTION AND BRAKING BASED ON MATLAB AND LABVIEW
}

\author{
LEI CHI \& WU MENG-LING \\ Institute of Railway and Urban Mass Transit, Tongji University, China
}

\begin{abstract}
This paper deals with the modeling and simulation of traction process and braking process. An underlying model based on Matlab-simulink is built which consists of a traction system model and a braking system model. The principle of modeling and logic of control designed in this paper is in order to achieve simulation of traction process and braking process. The modeling is simplified in order to reduce computational effort and perform real time simulation. A graphical user interface (GUI) based on Labview is designed, which is used to input model parameters, display operation status and simulation data. As a result of integrating the simulation of traction with braking, the modeling which can be used to simulate the real status of train provides a reference for setting subway stations and optimization of route.
\end{abstract}

Keywords: modeling, traction process, braking process, GUI, simulation.

\section{INTRODUCTION}

Simulation models have been used to simulate train traction or braking process over the years. Better understanding of the traction or braking process can be obtained during the developing stage of a traction or braking system via simulation, instead of carrying out expensive tests. Traction and braking controllers can also be developed based on the simulation model before online tests [1], [2]. Thus, the modeling problem of traction process and braking process has drawn researchers quite a lot of attention.

On the one hand, Wu et al. [3] has already built a train traction model for Tianjin Light Rail Transport based on mathematical formula, which is used for fault analysis. Lin [4] develops a model of metro traction system based on the physical components. Gui [5] aiming at urban rail transit traction calculation builds a train traction model based on force analysis. Piechowiak [6], [7] has developed a simulation model of a freight train based on the physical configuration of the brake system, which consists of complicated distributors and braking pipe. Pugi et al. [8] decomposes a freight train brake system into many subcomponents and builds a brake component library for brake system modelling via the Matlab-Simulink computer code. Wei [9] builds braking model according to pneumatic principle and carried out numerical simulation analysis. The braking model or traction model built by the above authors are all based on mathematical formula or physical principle. The veracity of model is influenced by the difference between theory and practice, and too much computational effort is needed to run those simulation models. In addition, no one establishes a model combining the traction with braking. This paper provides a model integrating traction with braking for the first time. The model is built according to the fitting curve of the traction characteristic and braking characteristic, which are based on the experimental data. The modeling approach according to experimental data makes the simulation close to the practical situation. The model also reduces calculated amount to a large extent, which needs much less computation time and facilitates real time simulation.

On the other hand, Tang et al. [10] carries out the simulation of high-speed train based on C\# via building a node network model. Gill and Goodman [11] develops a train operation 
simulation system, which is used for analyzing the performance of different handle level. Other researchers [12], [13] take the influence of line situation into account and develop the simulation of single vehicle operation. This paper takes simulation based on Matlab-Simulink and Labview, which makes the simulation compendiously, expandable, editable and easy to realize. The simulation simulates not only the relationship between the train handle and operation, but also the traction force and braking force. It provides a possibility for optimization of route and a reference for setting subway station.

\section{TRACTION AND BRAKING MODELING}

\subsection{Principle of modeling}

Because the main purpose of the model is to simulate the traction process and braking process, less important vehicle motions are not considered for simplification of the train model. The vehicle model is built as single-particle. The model is used to simulate a type of subway train in China. The subway train contains four motor vehicles and two trailer vehicles.

\subsection{Modeling of the traction system}

In order to reduce the computational effort of the simulation, the traction process is described in Fig. 1.

The traction instruction is sent out by controller as traction level. In the model traction level isn't stepless, and there are totally ten traction levels which is from one level to ten level. Different level means different traction force.

The traction force(F_traction) can be calculated as:

$$
\text { F_traction }=\mathrm{f}(\mathrm{v}) \text {. }
$$

In eqn (1), $\mathrm{f}(\mathrm{v})$ is a velocity(V)-related function, the fitting function is simplified based on experimental data according to actual measurement. The experimental data is shown in Table 1.

AW0, AW2, AW3 mean different working conditions of train. The fitting curve of Table 1 named traction characteristic curve is shown in Fig. 2. The traction system obtains $\mathrm{F}$-traction in the current velocity form the curve. And the curve shows the maximum value of $F_{-}$traction, the real traction force is linear interpolation from zero to the traction characteristic curve according to the current traction level.

The traction acceleration(a) can be calculated as:

$$
\mathrm{a}=\left(\mathrm{F}_{-} \text {traction }-\mathrm{R}\right) / \mathrm{W} \text {. }
$$

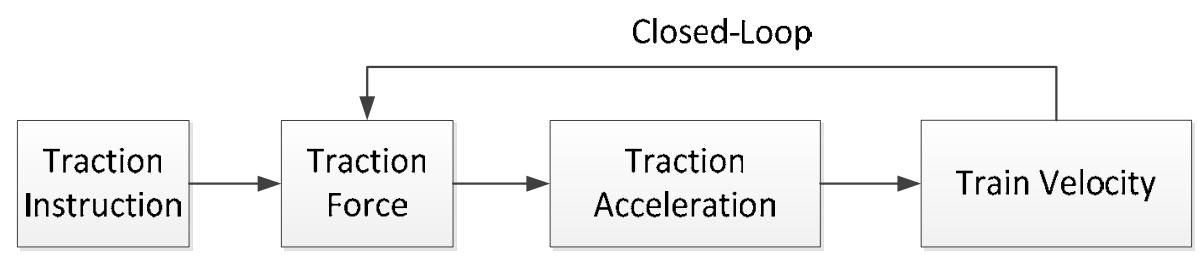

Figure 1: Control principle of traction. 
Table 1: F_traction - V experimental data.

\begin{tabular}{|c|c|c|c|c|c|c|c|c|c|c|c|}
\hline $\mathrm{V}(\mathrm{km} / \mathrm{h})$ & $\leq 60$ & 62 & 64 & 66 & 68 & 70 & 72 & 74 & 76 & 78 & 80 \\
\hline $\begin{array}{c}\text { F_traction } \\
(\mathrm{kN})\end{array}$ & 230 & 217 & 204 & 192 & 181 & 170 & 162 & 153 & 146 & 138 & 132 \\
\hline
\end{tabular}

\begin{tabular}{|c|c|c|c|c|c|c|c|c|c|c|c|}
\hline V(km/h) & $\leq 43$ & 44 & 48 & 52 & 56 & 60 & 64 & 68 & 72 & 76 & 80 \\
\hline $\begin{array}{c}\text { F_traction } \\
(\mathrm{kN})\end{array}$ & 323 & 315 & 289 & 266 & 248 & 230 & 204 & 181 & 162 & 146 & 138 \\
\hline
\end{tabular}

\begin{tabular}{|c|c|c|c|c|c|c|c|c|c|c|c|}
\hline $\mathrm{V}(\mathrm{km} / \mathrm{h})$ & $\leq 40$ & 44 & 48 & 52 & 56 & 60 & 64 & 68 & 72 & 76 & 80 \\
\hline $\begin{array}{c}\text { F_traction } \\
(\mathrm{kN})\end{array}$ & 345 & 315 & 302 & 278 & 257 & 230 & 204 & 181 & 162 & 146 & 132 \\
\hline
\end{tabular}

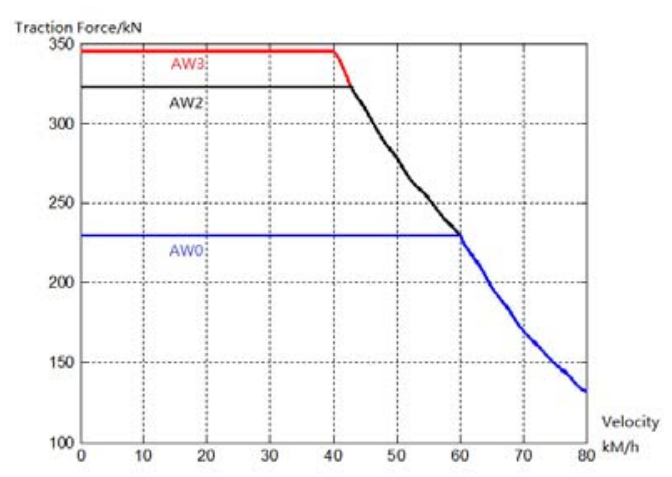

Figure 2: Traction characteristic curve.

Table 2: Weight of train.

\begin{tabular}{|c|c|c|}
\hline & $\mathrm{Wm}(\mathrm{t})$ & $\mathrm{Wt}(\mathrm{t})$ \\
\hline AW0 & 33 & 33 \\
\hline AW2 & 46.6 & 46.6 \\
\hline AW3 & 50.4 & 50.4 \\
\hline
\end{tabular}

In eqn (2), $\mathrm{R}$ represents basic operation resistance, $\mathrm{W}$ is weight of vehicle. According to JIS Standard, the basic operation resistance is following:

$$
\mathrm{R}=(16.18+0.2422 \mathrm{~V}) \mathrm{W}_{\mathrm{m}}+(7.65+0.0275 \mathrm{~V}) \mathrm{W}_{\mathrm{t}}+(0.275+0.0765(\mathrm{n}-1)) \mathrm{V}^{2} \text {. }
$$

In the eqn (3), $\mathrm{W}_{\mathrm{m}}$ is weight of motor vehicle, $\mathrm{W}_{\mathrm{t}}$ is weight of trailer vehicle, and $\mathrm{n}$ is number of vehicle. The weight of train under different simulation conditions are shown in Table 2. 
The traction acceleration acts on the train model of single-particle, which makes the system get the current velocity. The closed-loop based on velocity-traction force is completed.

In order to simulate the traction of train more realistic. The traction system model considers the following practical situation as well.

Starting state: when the train velocity is less than $5 \mathrm{~km} / \mathrm{h}$, a starting resistance which is related to weight of train is taken effect.

State of constant velocity: The model set a constant velocity signal. When the signal is effective, the train runs in constant velocity. When the train velocity be close to maximum design speed, the signal will come into force automatically.

\subsection{Modeling of the braking system}

In order to reduce the computational effort of the simulation, the braking process is described in Fig. 3.

The braking instruction is sent out by controller as braking level. In the model braking level isn't stepless, and there are totally seven braking levels which is from one level to seven level. Different level means different traction deceleration.

The braking deceleration based on the design deceleration is shown in Table 3 .

The braking force( $\mathrm{F}$ _braking) can be calculated as:

$$
\text { F_braking }=\mathrm{a} * \mathrm{~W}-\mathrm{R} \text {. }
$$

If braking level is emergency brake, pneumatic braking supplies all braking force. When braking level is one of $1 \mathrm{~N}$ to $7 \mathrm{~N}$ or fast brake, the braking system compares $\mathrm{F}$ braking with the maximum electric braking force( $\mathrm{FE}_{\max }$ braking) in the current velocity. If electric

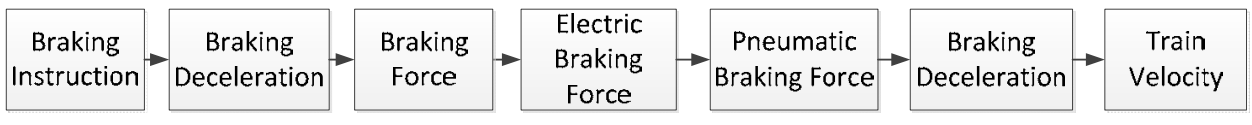

Figure 3: Control principle of braking.

Table 3: Design deceleration.

\begin{tabular}{|c|c|c|}
\hline \multirow{2}{*}{ Braking level } & \multicolumn{2}{|c|}{ Deceleration $(\mathrm{m} / \mathrm{s})$} \\
\cline { 2 - 3 } & $\mathrm{V}: 0 \sim 70 \mathrm{~km} / \mathrm{h}$ & $\mathrm{V}: 70 \sim 80 \mathrm{~km} / \mathrm{h}$ \\
\hline $1 \mathrm{~N}$ & 0.1667 & $0.0005787 * \mathrm{~V}+0.2072$ \\
\hline $2 \mathrm{~N}$ & 0.2639 & $0.0009259^{*} \mathrm{~V}+0.3287$ \\
\hline $3 \mathrm{~N}$ & 0.3611 & $0.0012731 * \mathrm{~V}+0.4502$ \\
\hline $4 \mathrm{~N}$ & 0.4583 & $0.0016782 * \mathrm{~V}+0.5758$ \\
\hline $5 \mathrm{~N}$ & 0.5528 & $0.0019676^{*} \mathrm{~V}+0.6905$ \\
\hline $6 \mathrm{~N}$ & 0.6500 & $0.0023148 * \mathrm{~V}+0.8120$ \\
\hline $7 \mathrm{~N}$ & 0.7472 & $0.0026620 * \mathrm{~V}+0.9336$ \\
\hline Fast brake & \multicolumn{2}{|c}{1.2} \\
\hline Emergency brake & \multicolumn{2}{|c}{1.2} \\
\hline
\end{tabular}


Table 4: Design deceleration.

\begin{tabular}{|c|c|c|c|c|}
\hline \multicolumn{1}{|c|}{ AW0 } \\
\hline FEmax_braking $(\mathrm{kN})$ & 0 & $39.75 *(\mathrm{~V}-7)$ & 318 & $-4.7 * \mathrm{~V}+647$ \\
\hline
\end{tabular}

AW2

\begin{tabular}{|c|c|c|c|c|}
\hline $\mathrm{V}(\mathrm{km} / \mathrm{h})$ & $\mathrm{V}<7$ & $7 \leq \mathrm{V}<15$ & $15 \leq \mathrm{V}<70$ & $\mathrm{~V} \geq 74$ \\
\hline FEmax_braking $(\mathrm{kN})$ & 0 & $34.925^{*}(\mathrm{~V}-7)$ & 297.5 & $-4.4 * \mathrm{~V}+623$ \\
\hline
\end{tabular}

AW3

\begin{tabular}{|c|c|c|c|}
\hline $\mathrm{V}(\mathrm{km} / \mathrm{h})$ & $\mathrm{V}<7$ & $7 \leq \mathrm{V}<15$ & $\mathrm{~V} \geq 15$ \\
\hline FEmax_braking $(\mathrm{kN})$ & 0 & $26.5 *(\mathrm{~V}-7)$ & 212 \\
\hline
\end{tabular}

braking force (FE_braking) isn't enough, the braking force will be supplemented by pneumatic braking force (FP braking) of trailer vehicle (two trailers equally) firstly. If braking force is still not enough, it will be supplemented by pneumatic braking force of motor vehicle (four motor vehicles equally) secondly [14]. The $\mathrm{FE}_{\text {max }}$ braking in different situation is shown in Table 4.

The real pneumatic braking force which is related to the brake shoe friction coefficient, leverage ratio, efficiency, effective area, brake cylinder number acts on the train model of single-particle with the electric braking force. The braking process is achieved.

\section{SIMULATION DESIGN}

\subsection{Simulation configuration}

The configuration of the simulation is shown in Fig. 4. The whole simulation consists of an underlying model built in Section 2 and a graphical user interface (GUI).

The underlying model is built based on the Matlab-Simulink and provides the mathematical foundation for the simulation. The GUI is developed using the Labview computer code and used to establish communication between a user and the simulation model. The parameters of model can be changed by a user via the GUI during simulation. The main parameters of model including input and output is shown in Table 5.

GUI(Labview)

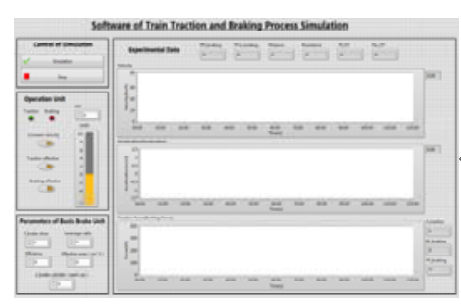

Underlying model(Matlab-simulink)

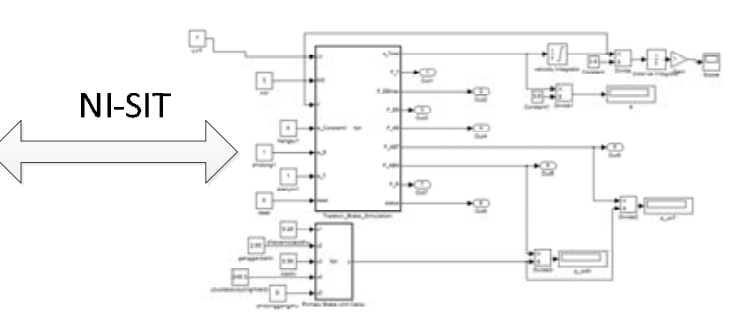

Figure 4: Configuration of the simulation. 
Table 5: Design deceleration.

\begin{tabular}{|c|c|c|c|}
\hline Parameters & Input/Output & Notation & Unit \\
\hline Braking level & Input & - & - \\
\hline Constant velocity & Input & - & - \\
\hline Traction effective & Input & - & - \\
\hline Braking effective & Input & - & - \\
\hline Brake shoe friction coefficient & Input & f_brake shoe & - \\
\hline Leverage ratio & Input & - & - \\
\hline Efficiency & Input & - & - \\
\hline Effective area & Input & - & $\mathrm{cm}^{2}$ \\
\hline Brake cylinder number & Input & n_brake cylinder & per vehicle \\
\hline Velocity & Output & V & $\mathrm{km} / \mathrm{h}$ \\
\hline Acceleration(deceleration) & Output & a(a') & $\mathrm{m} / \mathrm{s}^{2}$ \\
\hline Traction force & Output & F_traction & $\mathrm{kN}$ \\
\hline Electric braking force & Output & FE_braking & $\mathrm{kN}$ \\
\hline Pneumatic braking force & Output & FP_braking & $\mathrm{kN}$ \\
\hline
\end{tabular}

A software code, called Simulation Interface Toolkit (SIT), originally developed by the National Instruments (NI) corporation is used to facilitate the communication between the GUI and the underlying model [15].

\subsection{Graphical user interface}

A GUI designed based on the Labview composes of five function areas. The function of each area is designed as follows.

\subsubsection{Control of simulation}

The function area is shown in Fig. 5. The part is used for achieving the starting and stopping of the simulation via control the communication of SIT.

\subsubsection{Operation unit}

The function area is shown in Fig. 6. The part is applied to choose the working condition, set the level of traction and braking, control the effectiveness of traction or braking function and achieve the function of constant velocity operation. In addition, it shows the current statue of traction and braking.

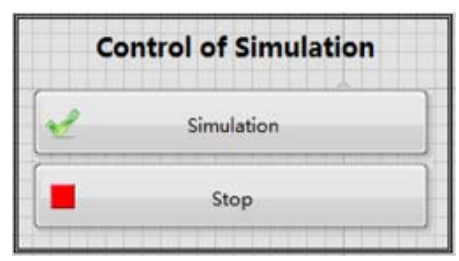

Figure 5: Control of simulation. 


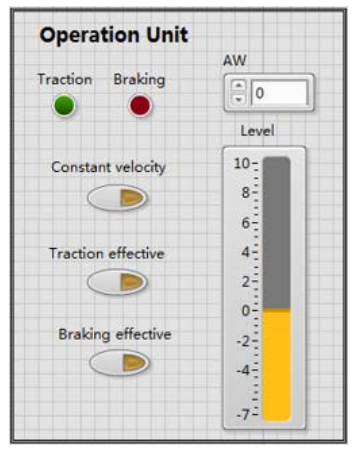

Figure 6: Operation unit.

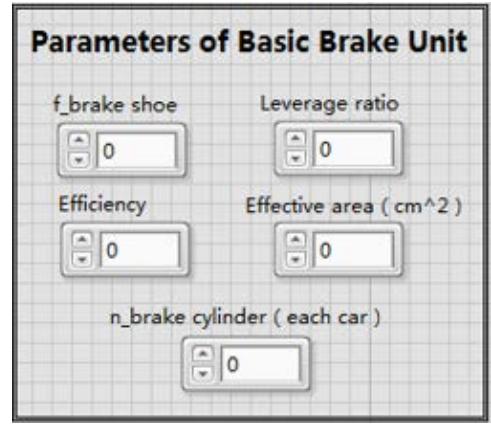

Figure 7: Parameters of basic brake.

\subsubsection{Parameters of basic brake}

The function area is shown in Fig. 7. The part is used for setting parameters of basic brake, such as the brake shoe friction coefficient, leverage ratio, efficiency, effective area, and brake cylinder number. The cylinder pressure can be calculated based on these parameters.

\subsubsection{Experimental dada}

The function area is shown in Fig. 8. The part is mainly applied to drawing the velocity-time curve, acceleration-time curve, traction force-time(braking force-time) curve according to the underlying model. In addition, it displays the trailer vehicle pneumatic brake force, the motor vehicle pneumatic braking force, the running distance, the running resistance and the cylinder pressure.

\subsubsection{Main interface of GUI}

The main interface of GUI is shown in Fig. 9. A whole process of traction, constant velocity operation, coasting and braking in the AW3 condition is simulated. It can be proved that the software can simulate the running state of the subway train. The results shown in the experimental data indicate that the model has the ability to simulate traction process and braking process. What needs illustration is that the red line in the braking force-time curve means electric braking force, and the green line in the curve means pneumatic braking force. It reflects the electro-pneumatic well. 


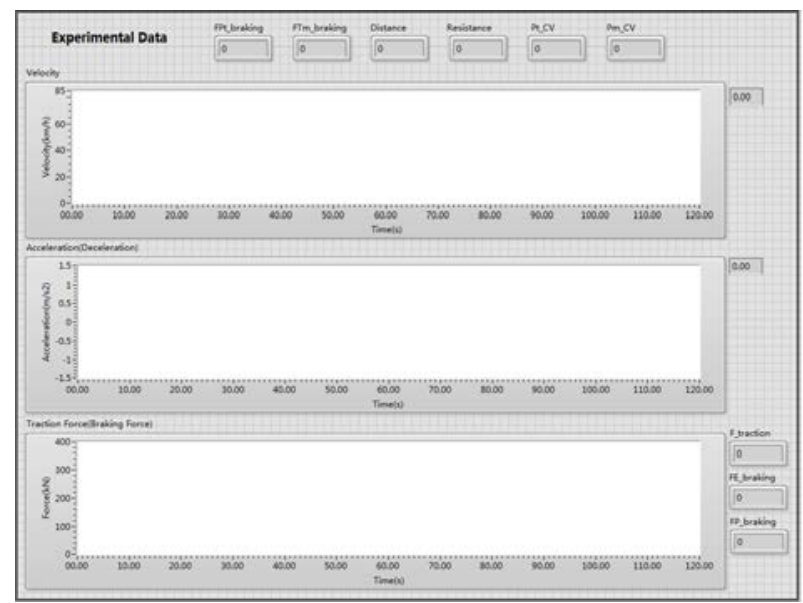

Figure 8: Experimental dada.

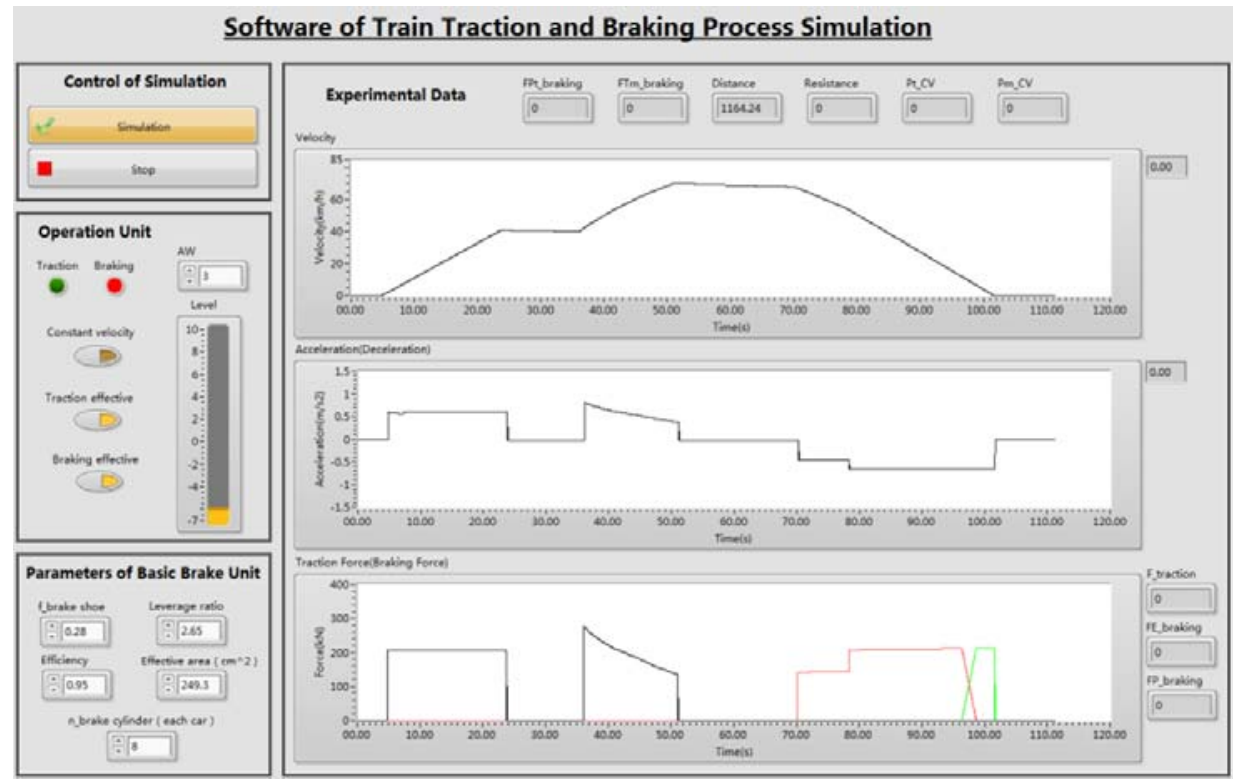

Figure 9: Main interface of GUI.

\section{SIMULATION APPLICATION}

To better verify the simulation performance of the model, a line test in one of Chinese subway route is carried out. In the test, the actual velocity of an operating subway train is measured by radar under vehicle. The actual traction and braking level are obtained from vehicle network by measurement system as well. The line test environment is shown in Fig. 10.

The line of subway train has 31 stations. Velocity and level information of train which make a round trip are recorded. The velocity of experiment is shown in Fig. 11. 
According to the traction and braking level information, the train operation in the same instruction and situation is simulated based on the model built in Section 2. Comparing experiment with simulation, a piece of intercepting information is shown in Fig. 12.

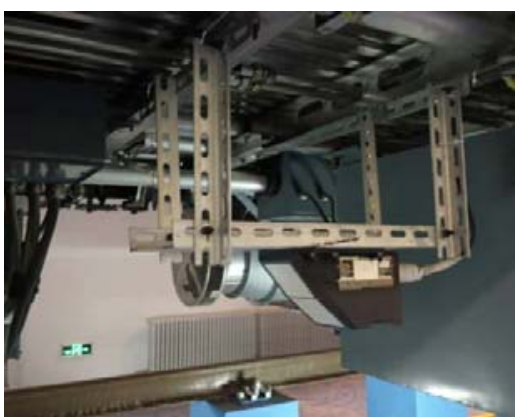

(a) Radar speed measuring device

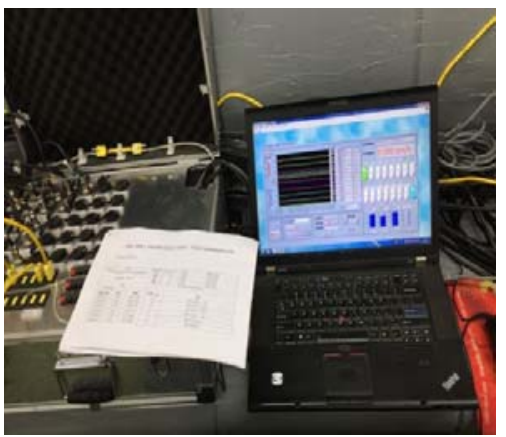

(b) Network measuring device

Figure 10: Line test environment.

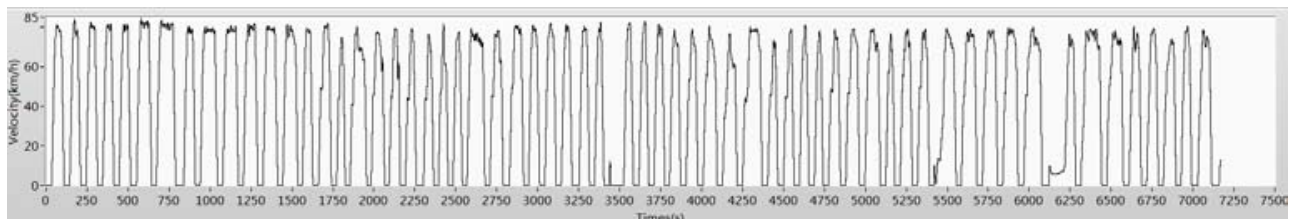

Figure 11: Velocity of experiment.

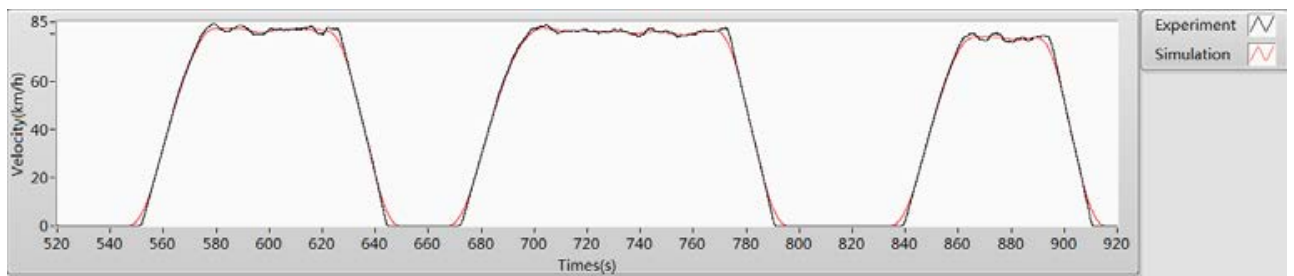

Figure 12: Comparing of experiment and simulation. 
As can be seen from Fig. 12, the model can simulate the operation of the subway train in actual line effectively. The information of subway train in each station is described clearly in the simulation. The administrator can adjust the location of each subway station and sets superior subway stations according to comparing the different train operation situation. Because the simulation can simulate the traction force, braking force and velocity of the train in the whole line, the railway line can be also optimized by simulation results to ensure the security of train operation and the rationality of line operation. In addition, the configuration of traction and braking can be programmed effectively.

\section{CONCLUSION}

This paper builds the model of subway train traction system according to experiment dada and takes consideration on practical situation. Model of braking system taking consideration of electro-pneumatic is built as well. The whole model integrated traction with braking based on Matlab-simulink is simplified in order to reduce computational effort and perform real time simulation. The GUI of the simulation, developed via Labview, is designed in order to control simulation, operate model, input model parameters, and display simulation results. The simulation simulates not only the relationship between the train handle and operation, but also the traction force and braking force. Finally, a real line experiment is conducted. The accuracy and effectiveness are proved via comparing experiment with simulation. The model and simulation provide a possibility for optimization of route and a reference for setting subway station.

\section{REFERENCES}

[1] Murtaza, M.A. \& Garg, S.B.L., Brake modelling in train simulation studies. Proceedings of the Institution of Mechanical Engineers, Part F: Journal of Rail and Rapid Transit, 203(2), pp.87-95, 1989. DOI: 10.1243/pime_proc_1989_203_215_02.

[2] Song, R., Yang, J. \& Fang, Y., Research on modelling of dynamic traction characteristics and test system of urban rail vehicles. Journal of the China Railway Society, 34(7), pp. 36-42, 2012.

[3] Wu, Z., Mao, M., Tao, S. \& Liu, Y., Digital simulation calculation of traction of vehicle of Tianjin light rail transport. Journal of Tongji University, 31(6), pp. 687691, 2003.

[4] Lin, W., Analysis modeling and optimization of metro traction system, 2010.

[5] Gui, X., Research and development of urban rail transit traction calculation system, 2015.

[6] Piechowiak, T., Pneumatic train brake simulation method. Vehicle System Dynamics, 47(12), pp. 1473-1492, 2009. DOI: 10.1080/00423110802600946.

[7] Piechowiak, T. Verification of pneumatic railway brake models. Vehicle System Dynamics, 48(3), pp. 283-299, 2010. DOI: 10.1080/00423110902780622.

[8] Pugi, L., Malvezzi, M., Allotta, B., Banchi, L. \& Presciani, P. A parametric library for the simulation of a union Internationale des Chemins de Fer (UIC) pneumatic braking system. Proceedings of the Institution of Mechanical Engineers, Part F: Journal of Rail and Rapid Transit, 218(2), pp. 117-132, 2004.

[9] Wei, W., Simulation model of train brake system. Journal of the China Railway Society, 25(1), pp. 38-42, 2003.

[10] Tang, J., Zhou, L., Dong, L. \& Zhou, Y., Simulation model and arithmetic of single high-speed train. China Railway Science, 33(3), pp. 109-114, 2012. 
[11] Gill, D. \& Goodman, C.J., Computer-based optimization techniques for mass transit railway signalling design. IEE Proceedings B Electric Power Applications, 139(3), pp. 261-275, 1992. DOI: 10.1049/ip-b.1992.0031.

[12] Mao, B., He, T. \& Yuan, Z., A General-purposed simulation system on train movement. Journal of the Railway Society, 22(1), pp. 1-6, 2000.

[13] Shi, H., Study on train operation and movement process simulation and its' optimization, 2006.

[14] Chen, J., Research on electro-pneumatic blend braking technology of the subway rail trains, 2013.

[15] Qu, L., Hu, R. \& Fan, F. Mixed Programming Technology of Labview and Matlab, China Machine Press: Beijing, 2011. 